\title{
Article
}

\section{Are physical performance and injury risk in a professional soccer team in match- play affected over a prolonged period of fixture congestion?}

Carling, C., Le Gall, F., and Dupont, G.

Available at http://clok.uclan.ac.uk/12294/

Carling, C. ORCID: 0000-0002-7456-3493, Le Gall, F., and Dupont, G. (2012) Are physical performance and injury risk in a professional soccer team in match-play affected over a prolonged period of fixture congestion?

International Journal of Sports Medicine, 33 (3). pp. 36-42. ISSN 0172-4622

It is advisable to refer to the publisher's version if you intend to cite from the work. http://dx.doi.org/10.1055/s-0031-1283190

For more information about UCLan's research in this area go to http://www.uclan.ac.uk/researchgroups/ and search for <name of research Group>.

For information about Research generally at UCLan please go to http://www.uclan.ac.uk/research/

All outputs in CLoK are protected by Intellectual Property Rights law, including Copyright law. Copyright, IPR and Moral Rights for the works on this site are retained by the individual authors and/or other copyright owners. Terms and conditions for use of this material are defined in the policies page.

\section{CLoK}

Central Lancashire online Knowledge www.clok.uclan.ac.uk

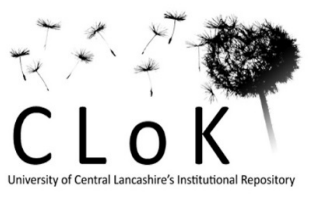


This is a pre-proof corrected manuscript, as accepted for publication, of an article published by Thieme Medical Publishers in International Journal of Sports Medicine on $19^{\text {th }}$ October 2011, available online: https://www.thieme-connect.com/DOI/DOI?10.1055/s-0031-1283190 PLEASE REFER TO THE PUBLISHED VERSION FOR CITING PURPOSES

Are physical performance and injury risk in a professional soccer team in match-play affected over a prolonged period of fixture congestion?

C. Carling ${ }^{1,2}$, F. Le Gall ${ }^{1}$, G. Dupont ${ }^{1,3}$

Affiliations ${ }^{1}$ LOSC Lille Métropole Football Club, Domain de Luchin, Camphin-enPévèle, France

${ }^{2}$ Institute of Coaching and Performance, University of Central Lancashire, Preston, United Kingdom

${ }^{3}$ Univ Lille Nord de France, UArtois, EA4488, 59000 Lille, France 


\begin{abstract}
In this study, the effects of a prolonged period of fixture congestion (8 successive official matches in 26-days) on physical performance and injury risk and severity in a professional soccer team were investigated. Computerised motion-analysis was used to analyse the overall distance covered and that run at light- $\left(0.0-11.0 \mathrm{~km} \bullet \mathrm{h}^{-1}\right)$; low- $(11.1$ $\left.14.0 \mathrm{~km} \bullet \mathrm{h}^{-1}\right)$; moderate- $\left(14.1-19.7 \mathrm{~km} \bullet \mathrm{h}^{-1}\right)$ and high-intensities $\left(\geq 19.8 \mathrm{~km} \bullet \mathrm{h}^{-1}\right)$ for the team as a whole. Distances were measured in metres per minute. Information on match injuries was recorded prospectively. The overall distance covered varied across successive matches $(\mathrm{p}<0.001)$ as more distance was run in games 4 and 7 compared to 2 and 3 respectively $\left(126.6 \pm 12.3 \mathrm{~m} \cdot \mathrm{min}^{-1}\right.$ and $125.0 \pm 13.2 \mathrm{~m} \cdot \mathrm{min}^{-1}$ vs. $116.0 \pm 8.0 \mathrm{~m} \bullet \mathrm{min}^{-1}$ and $\left.115.5 \pm 11.0 \mathrm{~m} \cdot \mathrm{min}^{-1}\right)$. Distance run in light-intensity exercise also varied $(\mathrm{p}<0.001)$ as more distance was covered in game 4 versus $1,2,3,5$ and $6\left(75.5 \pm 3.8 \mathrm{~m}^{\bullet} \mathrm{min}^{-1} \mathrm{vs}\right.$. $70.6 \pm 2.4 \mathrm{~m} \bullet \mathrm{min}^{-1}, 71.8 \pm 3.4 \mathrm{~m} \bullet \mathrm{min}^{-1}, 69.3 \pm 2.6 \mathrm{~m} \bullet \mathrm{min}^{-1}, 71.5 \pm 3.1 \mathrm{~m} \bullet \mathrm{min}^{-1}$, and $70.3 \pm 2.8$ $\left.\mathrm{m} \bullet \mathrm{min}^{-1}\right)$ and in game 8 versus game $3\left(73.1 \pm 3.8\right.$ vs. $\left.69.3 \pm 2.6 \mathrm{~m} \bullet \mathrm{min}^{-1}\right)$ respectively. When comparing match halves, there were no differences across games in overall or high-intensity distance covered and performance in these measures was similar for matches played before, during and after this period. Globally, no difference over the 8 games combined was observed between the reference team and opponents in any of the performance measures whereas the overall distance covered and that in low- (both $\mathrm{p}<0.001)$ and high-intensity running $(\mathrm{p}=0.040)$ differed in individual games. The incidence of match injury during the congested fixture period was similar to rates reported outside this period but the mean layoff duration of injuries was substantially shorter during the former $(\mathrm{p}<0.05)$. In summary, while the overall distance run and that covered at lower intensities varied across games, high-intensity running performance and injury risk were generally unaffected during a prolonged period of fixture congestion. These results might be linked to squad rotation and post-match recovery strategies in place at the present club.
\end{abstract}

Key terms: locomotor activity, motion analysis, epidemiology, trauma, football 


\section{Introduction}

In contemporary European professional soccer, teams can participate in over 60 competitive matches per season. Hence, there is potential for professional soccer players to experience residual fatigue over the playing season especially during dense competitive schedules [22]. Research has shown that participation in a soccer match results in muscle trauma and a reduction in the anaerobic performance of players with perturbations persisting up to 72 hours $[1,20]$. Therefore, one would expect a drop in measures of physical performance in competition when there is an insufficient recovery time between matches. Several investigations have examined the physical activity profiles of professional soccer players during intense periods of matches. Surprisingly perhaps, studies conducted in English [24], French [7], Scottish [11] and Spanish [27] players did not report any statistical differences in athletic performance across successive matches played in a short time. These findings suggest that professional players can cope physically even when the time-delay between matches is short. However, in these previous studies, physical performance was examined across only 2 or 3 consecutive games played over a 3-7 day time-scale. Multiple longitudinal observations over an extended period of time are required to provide a more comprehensive estimation of the between-match variability in competitive performance indices [16]. Fixture congestion in contemporary professional soccer means it is common for teams to participate in multiple matches over more prolonged periods than those frequently used in previous studies to examine variations in physical performance. Yet no performance data are available on match-to-match variability and therefore the capacity of teams to 'physically' cope with intense competitive schedules over an extended period of time. 
It has recently been suggested that professional soccer players regulate their physical efforts when participating in congested fixture periods [27]. While this selfimposition of efforts might partly explain the previously observed lack of a decline in physical performance during successive games with a short recovery period, no studies have verified this theory. Analysis of aggregated performance in multiple matches during periods of fixture congestion compared to that observed in matches played outside these periods would therefore be pertinent. In addition, none of the previous aforementioned studies that examined the effects of fixture congestion on athletic performance have investigated the potential confounding effects of opponent performance. Athletic performance has been shown to be directly related to the physical activity completed by opponent teams [4,25]. An investigation into the physical demands imposed by separate opposition teams in multiple games over a tight timeframe and the capacity of a reference team to directly respond to these demands is therefore warranted.

Fixture congestion is not only regarded as a threat to match performance but also to player health [13]. However, only limited and contrasting information is available on the effects of calendar congestion and injury rates in professional soccer. Research in French players has shown that a very short interval between fixtures ( $\leq 3$ days) did not result in a higher injury risk or layoff time per injury compared to a longer interval ( $\geq$ 4days) [9]. In contrast, injury incidence was approximately six-times higher in Scottish players playing 2 games in a 4-day period compared to peers in the same team who had not played a match for 6-days or more [11]. Further research is thus necessary to explore the effects on injury rates of playing multiple games with a short delay between matches and especially over a prolonged period of fixture congestion. Finally, player rotation strategies have been suggested as a potential means to aid in reducing 
injury rates as well as maintaining match performance during dense competitive schedules and therefore warrant investigation $[11,13]$.

In December 2009, the present French professional soccer team participated in 8 consecutive official matches (League and European competition) played over a 26-day period. Consequently, this competitive schedule provided a unique opportunity to analyse physical performance, injury rates, and squad rotation strategies during a prolonged period of fixture congestion. Four hypotheses based on measures of physical performance and injury rates and severity were tested: i) physical performance would differ across games over the 26-day period, ii) physical performance during the congested fixture period would differ compared to in games before and after this period, iii) physical performance of opposition teams would be greater than the reference team over the prolonged period of fixture congestion; iv) match injury rates and severity would be greater during the prolonged period of fixture congestion compared to outside this period.

\section{Methods}

Participants and match sample

Physical performance and injuries sustained in official competition were analysed in players from a professional soccer team that competed in the French League 1 (highest standard in French soccer). Performance data were collected from 6 French League 1 and 2 UEFA Europa League games played consecutively over a 26-day period. Matches were played on the 28/11/2009, 02/12/2009, 06/12/2009, 10/12/2009, 13/12/2009, 17/12/2009, 20/12/2009 and 23/12/2009). Competition commenced at either 5PM, 7PM or 9PM. Data were also collected for matches before $(n=9)$ and after $(n=13)$ the prolonged period of fixture congestion. 
This study generally meets the standards for research cited in the International Journal of Sports Medicine [18]. However, usual appropriate ethics committee clearance required by the International Journal of Sports Medicine was not sought as the present data arose as a condition of employment in which player performance was routinely measured over the course of the competitive season [30]. Nevertheless, to ensure team and player confidentiality, all match performance and injury data were anonymised before analysis.

\section{Match performance data collection procedures and measures}

A semi-automatic computerised tracking system for soccer (AMISCO Pro ${ }^{\circledR}$, SportUniversal Process, Nice, France) was used to characterise match activity profiles in the reference team. This multiple-camera system passively tracks the movements of every player using a sampling rate of $10.0 \mathrm{~Hz}$ over the entire course of matches. The workings, accuracy and reliability of the AMISCO Pro ${ }^{\circledR}$ system in measuring player movements in elite soccer competition have been described in detail elsewhere $[6,26]$.

The measures of physical performance in match-play for the team as a whole included an analysis per minute in metres $(\mathrm{m})$ of the overall distance covered and distances run in light-intensity $\left(0.0-11.0 \mathrm{~km} \bullet \mathrm{h}^{-1}\right)$; low-intensity $\left(11.1-14.0 \mathrm{~km} \bullet \mathrm{h}^{-1}\right)$; moderate-intensity $\left(14.1-19.0 \mathrm{~km} \bullet \mathrm{h}^{-1}\right)$ and high-intensity $\left(>19.1 \mathrm{~km} \bullet \mathrm{h}^{-1}\right)$ [3]. Data on the overall distance covered and that run in high-intensity activity respectively were collected for each half of games. Finally, the overall distance covered in individual ball possession was recorded. Only match performance in outfield players was included for analysis. 


\section{Injury collection procedures}

First-team match injuries were considered and inclusion criteria were those injuries leading to an outfield player being unable to fully participate in future training or matches (i.e. time-loss injury). Individual exposure time to match-play was collected to calculate injury incidence. Injuries are thereby presented as the number of injuries per 1000 hours exposure time. The type, location, and severity of the injury (layoff time) were prospectively recorded by the team physician, the latter depending on the number of days the player was absent from and unable to take full part in collective training or competition. All injuries were followed until the final day of rehabilitation. Finally, the cause (contact or non-contact) of injuries was recorded. The methodologies and definitions of injury used in the present study closely follow those recommended by International Soccer Injury Consensus Groups [15,17].

\section{After and between match procedures}

Recovery procedures employed post and between matches in the present club are based on those previously described in professional soccer [11] and elite academy players [2]. Contrast therapy (hot and cold water immersion) [2] was performed after match-play and lower-limb compression garments were worn by players [11]. In addition to these techniques, players generally had a Jacuzzi, a whole-body manual massage intervention and used lower-limb compression garments on the days between matches. When rest days were not imposed between competition, players performed short low-intensity training sessions (cycling and/or tactical/technical drills) and had video feedback sessions. Immediately after each match was completed, participating players consumed fluids and high-glycemic index carbohydrate foods and proteins and nutritional advice 
was provided to ensure that players had adequate nutrient and fluid intake over the 26day period [11].

\section{Statistical Analyses}

All statistical analyses were conducted using SigmaStat 3.5 (Systat Software, Point Richmond, California). Results are reported as means and standard deviations unless otherwise stated (mean \pm SD). Before using parametric tests, the Kolmogorov-Smirnov test completed by Lilliefors' correction was used to evaluate normality of distribution of the data. A one-way repeated measures ANOVA was used to compare outcome measures in each category of physical performance (overall distance covered per minute and that in light-; low- moderate- and high-intensity running and in individual ball possession) across: 1) 8 games played over the 26-day period, and; 2) games played before $(n=9)$, during $(n=8)$ and after $(n=13)$ the congested fixture period. A two-way repeated measures ANOVA was used to investigate changes in the overall distance covered and that run in high-intensity exercise across match halves over the 8 games played in a 26-day period. A two-way repeated measures ANOVA was additionally employed to compare outcome measures in each category of physical performance between the reference team and opposition teams over the 8 games. Finally, a paired ttest was used to compare injury incidence and layoff time for matches during and outside the congested fixture period. Follow-up post hoc univariate analyses using Tukey's Honestly Significant Difference test were used where appropriate. Statistical significance was set at $\mathrm{p}<0.05$. Coefficients of variation $(\mathrm{CV})$ and their $95 \%$ confidence intervals were calculated using the spreadsheet developed by Hopkins (19) to examine variability across matches for the measures of physical performance [16]. Cohen's d effect sizes for identified statistical differences were determined. When calculating 
effect sizes, pooled standard deviations were applied due to the absence of a control group. Effect sizes (ES) with values of $0.2,0.5$, and 0.8 were considered to represent small, medium, and large differences respectively [10].

\section{Results}

Player participation

Over the 26-day period, the total exposure time to match-play for all players was 139.3 hours. Altogether, 19 players from a squad of 26 professional players (73.1\%) participated in at least 1 or more matches and 2 players $(1$ goalkeeper and 1 centraldefender) completed every game. In addition, 6 players participated in every game either as a starter or substitute, and 8 players participated in $75 \%$ or more of the total number of minutes ( 8357 mins) played by the team. No sending offs occurred but two players incurred a 1-match suspension for accumulation of cautions. The maximum number of substitutes was used in every match and all substitutions were made in the second half.

\section{Match performance}

Across the 8 successive matches, a difference was reported for the overall distance covered $(\mathrm{p}<0.001)$. More distance was run both in games 4 and 7 compared to 2 and 3 respectively (ES for these differences ranged from 0.8-1.0) (Table 1). The distance covered at light-intensities also varied across games $(\mathrm{p}<0.001)$ with more distance run in game 4 versus 1, 2, 3, 5 and 6 and in game 8 versus game 3 (ES for these differences ranged from 1.0-1.9). No differences were reported for distance covered in high-intensity, moderate or low-intensity running or that in individual possession of the ball although the latter approached significance $(p=0.059)$. The respective mean 
coefficient of variations across the 8 games for the overall distance run, distance run in high-intensity matches and in ball possession notably were: $5.7 \%$ (CI 4.9-7.0\%), 33.5\% (CI 28.1-41.9\%) and 70.0\% (CI 57.6-90.3\%).

Table 1 about here.

The comparison of physical performance in matches played before, during and after a prolonged period of fixture congestion showed no difference for the overall distance run $(\mathrm{p}=0.990)$ or that covered in high-intensity $(\mathrm{p}=0.442)$, moderate-intensity $(\mathrm{p}=0.424)$, low-intensity $(\mathrm{p}=0.453)$, light-intensity $(\mathrm{p}=0.059)$ running or in individual possession of the ball $(\mathrm{p}=0.617)$. The coefficients of variation for the accumulated means of performance for matches played before, during and after the prolonged period of fixture congestion were $2.0 \%$ (CI 1.5-3.0) for the overall distance run and $10.4 \%$ (CI 7.9-16.1\%) for the distance run in high-intensity respectively.

Table 2 about here.

The overall distance run was similar between the $1^{\text {st }}$ and $2^{\text {nd }}$ half over all 8 games combined $\left(119.6 \pm 8.0 \mathrm{~m} \cdot \mathrm{min}^{-1}\right.$ vs. $\left.120.0 \pm 12.0 \mathrm{~m} \bullet \mathrm{min}^{-1}, \mathrm{p}=0.728\right)$ and no changes were observed for distance covered between halves in any of the successive matches $(\mathrm{p}=0.175)$. Similarly, the distance covered in high-intensity activity did not differ between the $1^{\text {st }}$ and $2^{\text {nd }}$ half over all 8 games combined $\left(10.9 \pm 3.1 \mathrm{~m}^{\circ} \mathrm{min}^{-1} \mathrm{vs}\right.$. $13.0 \pm 4.8 \mathrm{~m}^{\circ} \mathrm{min}^{-1}, \mathrm{p}=0.383$ ) and no differences were observed for this measure of performance between halves in any of the individual matches $(\mathrm{p}=0.189)$. 
No differences in means for the 8 games combined were observed between the reference team and opponents for any of the performance measures: overall distance $\left(120.7 \pm 8.4 \cdot \mathrm{min}^{-1}\right.$ vs. $\left.118.1 \pm 7.1 \mathrm{~m} \bullet \mathrm{min}^{-1}, \quad \mathrm{p}=0.122\right)$ and distance in high-intensity $\left(11.0 \pm 2.9 \quad\right.$ vs. $\left.\quad 10.4 \pm 2.3 \mathrm{~m} \bullet \mathrm{min}^{-1}, \quad \mathrm{p}=0.141\right), \quad$ moderate-intensity $\quad(19.6 \pm 4.4 \quad$ vs. $\left.18.6 \pm 3.1 \mathrm{~m} \cdot \mathrm{min}^{-1}, \mathrm{p}=0.268\right)$, low intensity $\left(18.3 \pm 2.0\right.$ vs. $\left.17.6 \pm 2.1 \mathrm{~m} \bullet \mathrm{min}^{-1}, \mathrm{p}=0.380\right)$ and light-intensity $\left(71.8 \pm 1.8\right.$ vs. $\left.71.5 \pm 2.41 \mathrm{~m} \bullet \mathrm{min}^{-1}, \mathrm{p}=0.150\right)$ movement. In contrast, the overall distance covered varied across individual games $(\mathrm{p}<0.001)$. More distance was covered in match 6 by the opposition $\left(131.5 \pm 13.2 \mathrm{~m} \bullet \mathrm{min}^{-1}\right.$ vs. $119.8 \pm 7.8 \mathrm{~m} \cdot \mathrm{min}^{-1}$, $\mathrm{p}<0.01, \mathrm{ES}=0.7)$ whereas this was the case for the reference team in match 5 $\left(122.0 \pm 13.9 \mathrm{~m} \bullet \mathrm{min}^{-1}\right.$ vs. $\left.115.2 \pm 9.6 \mathrm{~m} \bullet \mathrm{min}^{-1}, \mathrm{p}<0.05, \mathrm{ES}=0.6\right)$. Similarly, the distance covered in high-intensity running varied across successive games $(\mathrm{p}=0.040)$ with the distance run in match 6 being greater in the opposition $\left(13.6 \pm 5.6 \mathrm{~m}^{\bullet} \mathrm{min}^{-1} \mathrm{vs}\right.$. $\left.10.9 \pm 3.9 \mathrm{~m}^{\prime} \mathrm{min}^{-1}, \mathrm{p}<0.05, \mathrm{ES}=0.6\right)$. Low-intensity distance also varied across successive games $(\mathrm{p}<0.001)$ as the overall distance run per minute in match 6 was greater in the opposition $\left(22.9 \pm 6.1 \mathrm{~m} \cdot \mathrm{min}^{-1}\right.$ vs. $\left.17.7 \pm 2.0 \mathrm{~m} \bullet \mathrm{min}^{-1}, \mathrm{p}<0.001, \mathrm{ES}=1.2\right)$ while more distance was covered by the reference team in match $8\left(18.4 \pm 3.3 \mathrm{~m}^{\circ} \mathrm{min}^{-1}\right.$ vs. $\left.15.2 \pm 3.2 \mathrm{~m} \bullet \mathrm{min}^{-1}, \mathrm{p}<0.05, \mathrm{ES}=1.0\right)$. Distances covered in light- $(\mathrm{p}=0.487)$ and moderateintensity exercise $(\mathrm{p}=0.074)$ did not differ between the reference team and opponents in any of the games.

In opponent teams, the mean coefficient of variation across the 8 games for the overall distance run and distance run in high-intensity matches respectively was: $7.6 \%$ (CI 6.5-9.3\%) and 34.3\% (CI 28.7-42.9\%).

Match-play injuries 
Of the 19 players who participated in one or more of the matches in the series, $26.3 \%$ sustained an injury. A total of 7 match injuries were reported over the 26-day period. The incidence of injury across the prolonged period of fixture congestion was similar to that reported in matches played outside the study period (50.3 versus 49.8 per 1000 hours exposure, $\mathrm{p}=0.940$ ). The mean layoff duration for injuries was shorter for matches during compared to those outside the study period $(2.0 \pm 1.5$ days vs. $7.9 \pm 14.6$ days, $\mathrm{p}=0.043, \mathrm{ES}=0.6$ ). The majority of injuries were classed as minor (6 out of 7 , $85.7 \%$ ) with only one injury requiring a longer layoff period (5 days in total). Injuries included: 4 contusions affecting the quadriceps (1), knee (1) and foot (2) regions, 2 muscle strains affecting the groin (1) and hamstrings (1) regions and 1 sprain affecting the ankle region. All contusions were sustained after direct contact with an opponent whilst both strain and sprain injuries were incurred in non-contact situations.

\section{Discussion}

This study is unique as it is the first to investigate variations in physical performance and injury risk and severity in a professional soccer team over a prolonged period of fixture congestion: 8 successive matches over a 26-day period. The major findings were that the overall distance covered per minute and that in light-intensities varied across games whereas the distance covered in high-intensity running was unchanged. The overall distance covered and distance run in high-intensity exercise across match halves were unaffected during the congested fixture period and performance in these two measures did not differ for matches played before, during and after the prolonged period of fixture congestion. Performance in all physical performance measures was globally consistent in relation to the performance of opponents but the overall distance covered and that in low- and high-intensity running 
did vary across individual games. While injury rates in competition during the congested period of fixtures were similar to that reported in matches outside this period, the mean layoff duration of injuries was substantially shorter during the congested fixture period.

In the present study, the overall distance run per minute and that covered at light-intensities varied across 8 consecutive games played over a 26-day period. This result suggests that overall physical performance was affected for the team as a whole during a prolonged period of fixture congestion. Indeed, substantial differences were observed between matches (mean coefficient of variation of $5.7 \%$ across 8 games) and the present team was statistically outperformed by its opponents in one match. However, the overall distance covered by the reference team was lowest in the $2^{\text {nd }}$ and $3^{\text {rd }}$ games respectively and was actually higher in the final versus the first game in the series. Therefore, these variations in overall running performance might be linked to other factors rather than residual fatigue accumulated over the sequence of games. Changes over the consecutive games in the reference team's choice of starting line-up and tactics and/or in the specific physical and skill demands, playing style and team formation imposed by 8 separate opponents $[4,16,25]$ could explain these variations.

The overall distance run per player per half did not differ over the study period showing that the team was able to consistently maintain overall performance in the second-half of matches throughout the 8 successive matches. In addition, the overall distance run was similar when compared to that observed in games played both before and after the period of fixture congestion. Importantly, variability in this measure of physical performance across games was higher in opponent teams yet the reference team was generally able to respond to these changing physical demands as the team ran more distance overall in 6 out of 8 matches. Taken together, these results generally 
suggest that the present team was able to maintain overall physical performance even when subjected to a high number of games within a short time period.

The lack of a statistical difference in high-intensity running performance across the 8 successive matches for the team as a whole is generally in line with previous findings showing that high-intensity activity profiles are not affected by a short timeframe between successive professional soccer matches [7,11,24,27]. However, these previous studies investigated sporadic congested fixture schedules and only analysed high-intensity performance across two or three consecutive matches within a short timeframe. The findings from the present report are therefore noteworthy as these are the first to show that professional soccer players are generally able to maintain highintensity running performance over a prolonged period of fixture congestion. The relatively large variation in the distance run high-intensity reported across the 8 games (mean coefficient of difference of $33.5 \%$ ) nevertheless merits attention. Indeed, the large natural variability inherent to high-intensity running exercise in professional soccer could have masked any real changes in physical performance across the 8 consecutive matches. A larger sample size than the one used in the present study combined with a more detailed breakdown of composite high-intensity activity into discrete components (e.g., high-speed running, sprinting) might be necessary to enable better detection of real systematic variations in high-intensity running performance during periods of fixture congestion [16].

In addition to the lack of change in high-intensity running distance across the 8 consecutive games, performance in this measure was also comparable to that in matches played both before and after the extended period of fixture congestion and was maintained in the second-half of the 8 successive games. Furthermore, the reference team outperformed the opposition in 6 out of 8 games in high-intensity running 
performance. Overall, the reference team performed approximately $5 \%$ more distance in high-intensity exercise across the 8-games again, suggesting that performance in this measure was maintained. Further research is nevertheless recommendable to investigate whether inter-individual changes occur in physical performance for individual players participating in several consecutive matches over a short period. Similarly, analysis of the effects of individual playing position on variations in competitive running performance over a prolonged period of fixture congestion is warranted. Indeed, related research in professional soccer has reported substantial differences in match-to-match variability in high-intensity exercise across playing positions [16].

Several explanations for these findings can be forwarded including player rotation strategies either due to tactical choice and/or forced changes due to injury or suspension which might have kept the team 'fresh' as a whole and/or the post-match recovery techniques in place at the present club. It has been suggested that coaches, sports scientists, and medical teams should consider player rotation during fixture congestion to aid in maintaining health and performance $[11,13]$. Over the present series of matches, 19 players were used in total, only 6 players participated in every game as a starter or substitute, and a single outfield player completed every game. These player rotation practices would therefore appear to have contributed to the maintaining of physical performance across the multiple games. In addition, all players who participated in competition benefited from the implementation of systematic evidencebased post-match recovery procedures described earlier. When physical performance is likely to be impaired as a consequence of insufficient recovery time between matches, recovery interventions during the post-game period can provide a benefit to performance in the subsequent match [11]. Immediately after each match was 
completed, contrast bathing immersion was used as this can minimize player perception of leg soreness and general fatigue associated with playing successive matches [28]. Two related studies conducted in highly-trained elite youth [2] and amateur junior soccer players [29] have shown that post-match recovery interventions using hydrotherapy and/or cryotherapy techniques (e.g., sauna, cold water immersion, jacuzzi) were effective in maintaining running performance in consecutive games played within a short time delay. However, while the present evidence tends to provide support for the use of the present post-match recovery techniques to maintain athletic performance during a prolonged period of fixture congestion, further experimental research using a control group in whom no recovery interventions are performed is necessary.

Further explanations for the lack of a decline in high-intensity running performance across 8 successive matches might include the regulation of movement behaviour by players in the knowledge that they will be required to participate in successive games separated by a short interval [27]. However, running performance did not statistically differ to that observed in games played outside this period suggesting habitual performance was maintained despite fixture congestion. The physical efforts of substitutes might also have contributed to these findings as research has shown that replacement players can play a significant role in maintaining and/or increasing running performance at high-intensities [5,23]. Additional analyses on the present dataset show that this could have been the case as the distances run at high-intensities over the total time played by substitutes was substantially greater than those covered by the players they directly replaced $(15.2 \pm 5.8$ vs. $11.3 \pm 2.9$ metres per minute, $\mathrm{p}=0.014)$.

In a study of match injury in 23 professional European soccer clubs, an incidence of approximately 28 injuries per 1000hours competition has been reported [12] compared to $\sim 50$ per 1000 hours in the present study suggesting that the present 
players were generally more at risk of sustaining injury in match-play. However, injury rates in competition during the congested fixture period were similar to those observed in matches outside this period. This finding is partly in contrast with the results from a related study in that sporadic fixture congestion was associated with a significantly higher incidence of injuries [11]. In addition, only a small percentage of the total number of working days was lost (2.9\%) and a single match missed due to injury. Furthermore, only 3 non-contact injuries were sustained and the mean layoff of injuries sustained in matches during the congested fixture period was significantly shorter than that observed in matches outside this period. These encouraging findings generally lend support to previous research conducted in the present club which showed that sporadic congested fixture schedules do not affect injury rates or severity [9]. Again, effective player rotation policies and recovery strategies as well as controlled functional injury prevention and rehabilitation protocols [8] currently in place at the present club might have contributed to these findings.

In summary, this study provided a valuable opportunity to study physical performance, injury risk and severity in match-play over a prolonged period of fixture congestion. Physical performance and injury rates were generally unaffected therefore assuring that coaches, support staff and players alike that in a professional setting, highperformance teams can cope with a congested playing calendar. As a whole, these results also lend support to findings observed in professional Spanish soccer in that players are capable of coping with a busy match schedule as the results of Spanish teams in official competition were not affected by fixture congestion [21]. Indeed, a total of 7 victories and 1 defeat were recorded by the present club over the 8 successive games (27 goals scored versus 7 conceded) showing that the team coped well with a dense and prolonged match calendar. Additional research is nevertheless necessary 
using a larger sample of clubs and across different countries as the present cohort included players from one club. The patterns observed therefore, might only be a reflection of this particular team. Finally, an analysis of the potential variations in physiological responses to match-play across a similar prolonged period of fixture congestion is also merited. Data on objective markers of fatigue such as plasma creatine kinase concentration [14] combined with subjective measures of performance (e.g., rating of perceived exertion and sleep quality) could provide additional information on the individual and team responses to fixture congestion. 


\section{References}

1. Ascensão A, Rebelo A, Oliveira E, Marques F, Pereira L, Magalhães J. Biochemical impact of a soccer match - analysis of oxidative stress and muscle damage markers throughout recovery. Clin Biochem. 2008; 41: 841-851

2. Buchheit M, Horobeanu C, Mendez-Villanueva A, Simpson BM, Bourdon PC. Effects of age and spa treatment on match running performance over two consecutive games in highly trained young soccer players. J Sports Sci 2011; 29: $591-598$

3. Carling $C$. Analysis of physical activity profiles when running with the ball in a professional soccer team. J Sports Sci 2010; 28: 319-326

4. Carling $C$. Influence of opposition team formation on physical and skill-related performance in a professional soccer team. Eur J Sports Sci 2011; 11: 155-164

5. Carling C, Bloomfield J. Work-rate of substitutes in elite soccer: A preliminary study. J Sci Med Sport 2010; 13: 253-255

6. Carling C, Bloomfield J, Nelsen L, Reilly T. The role of motion analysis in elite soccer: Contemporary performance measurement techniques and work-rate data. Sports Med, 2008; 38: 839-862

7. Carling $C$, Dupont $G$. Are declines in physical performance associated with a reduction in skill-related performance during professional soccer match-play? J Sports Sci, 2011; 29: 63-71

8. Carling $C$, Le Gall F, Orhant E. A four-season prospective study of muscle strain reoccurrences in a professional football club. Res Sports Med 2011; 19: 92-102 
9. Carling C, Orhant E, Le Gall F. Match injuries in professional soccer: interseasonal variation and effects of competition type, match congestion and positional role. Int J Sports Med 2010; 31: 271-276

10. Cohen J. Statistical power analysis for the behavioural sciences. 2nd ed. Hillsdale, NJ: Lawrence Erlbaum; 1988

11. Dupont G, Nedelec M, McCall A, McCormack D, Berthoin S, Wisl $\phi f f U$. Effect of 2 soccer matches in a week on physical performance and injury rate. Am J Sports Med. 2010; 38: 1752-1758

12. Ekstrand J, Hägglund $M$, Waldén $M$. Injury incidence and injury patterns in professional football: the UEFA injury study. Br J Sports Med 2011; 45: 553558

13. Ekstrand J, Waldén M, Hägglund M. A congested football calendar and the wellbeing of players: Correlation between match exposure of European footballers before the World Cup 2002 and their injuries and performances during that World Cup. Br J Sports Med 2004; 38: 493-497

14. Fatouros IG, Chatzinikolaou A, Douroudos II, Nikolaidis MG, Kyparos A, Margonis $K$, Michailidis $Y$, Vantarakis A, Taxildaris $K$, Katrabasas I, Mandalidis D, Kouretas D, Jamurtas AZ. Time-course of changes in oxidative stress and antioxidant status responses following a soccer game. J Strength Cond Res 2010; 24: 3278-3286

15. Fuller CW, Ekstrand J, Junge A, Andersen TE, Bahr R, Dvorak J, Hägglund M, McCrory $P$, Meeuwisse WH. Consensus statement on injury definitions and data collection procedures in studies of football (soccer) injuries. Br J Sports Med 2006; 40: 193-201 
16. Gregson W, Drust B, Atkinson G, Salvo VD. Match-to-match variability of highspeed activities in premier league soccer. Int J Sports Med. 2010; 31: 237-242.

17. Hägglund M, Walden M, Bahr R, Ekstrand J. Methods for epidemiological study of injuries to professional football players: developing the UEFA model. $\mathrm{Br} \mathrm{J}$ Sports Med 2005; 39: 340-346

18. Harriss DJ, Atkinson G. International Journal of Sports Medicine - Ethical Standards in Sport and Exercise Science Research. Int J Sports Med 2009; 30: $701-702$

19. Hopkins WG. Reliability for consecutive pair of trials (Excel Spreadsheet). In: A new view of Statistics. Sportsci.org: Internet Society for Sport Science, sportsci.org/resource/stats/xrely.xls, 2000.

20. Ispirlidis I, Fatouros IG, Jamurtas AZ, Nikolaidis MG, Michailidis I, Douroudos I, Margonis K, Chatzinikolaou A, Kalistratos E, Katrabasas I, Alexiou V, Taxildaris $K$. Time-course of changes in inflammatory and performance responses following a soccer game. Clin J Sport Med 2008; 18: 423-431

21. Lago-Peñas $C$. Consequences of a busy soccer match schedule on team performance: Empirical evidence from Spain. Int SportMed J 2009; 10: 866-894

22. Lazarim FL, Antunes-Neto JM, da Silva FO, Nunes LA, Bassini-Cameron A, Cameron LC, Alves AA, Brenzikofer $R$, de Macedo DV. The upper values of plasma creatine kinase of professional soccer players during the Brazilian National Championship. J Sci Med Sport 2009; 12: 85-90

23. Mohr M, Krustrup P, Bangsbo J. Match performance of high-standard soccer players with special reference to development of fatigue. J Sports Sci 2003; 21: $519-528$ 
24. Odetoyinbo K, Wooster B, Lane A. The effect of a succession of matches on the activity profiles of professional soccer players. In: Reilly T, Korkusuz F (eds.) Science and Football VI. Routledge, UK 2007; 105-108

25. Rampinini E, Coutts AJ, Castagna C, Sassi R, Impellizzeri FM. Variation in top level soccer match performance. Int J Sports Med 2007; 28: 1018-1024

26. Randers MB, Mujika I, Hewitt A, Santisteban J, Bischoff R., Solano R, Zubillaga A, Peltola E, Krustrup P, Mohr M. Application of four different football match analysis systems: A comparative study. J Sports Sci 2010; 28: 171-182

27. Rey E, Lago-Peñas C, Lago-Ballesteros J, Casais L, Dellal A. The effects of a congested fixture period on the activity of elite soccer players. Biol Sport, 2010; 27: 181-185

28. Rowsell GJ, Coutts AJ, Reaburn P, Hill-Haas SV. Effect of cold-water immersion on physical performance between successive matches in junior highperformance soccer players. J Sports Sci 2009; 27: 565-573

29. Rowsell GJ, Coutts AJ, Reaburn P, Hill-Haas S. Effect of post-match cold-water immersion on subsequent match running performance in junior soccer players during tournament play. J Sports Sci 2011; 29: 1-6

30. Winter EM, Maughan RJ. Requirements for ethics approvals. J Sports Sci 2009; 27: 985 
Table 1: Changes in measures of physical performance in a reference team over a prolonged congested fixture period of 8 successive matches in 26-days.

\begin{tabular}{|c|c|c|c|c|c|c|c|c|c|c|}
\hline Distances & Match 1 & Match 2 & Match 3 & Match 4 & Match 5 & Match 6 & Match 7 & Match 8 & Statistical & Post hoc \\
\hline Covered & 28/11/09 & 2/12/09 & $6 / 12 / 09$ & $10 / 12 / 09$ & $13 / 12 / 09$ & $17 / 12 / 09$ & 20/12/09 & 23/12/09 & Difference & Difference \\
\hline Overall distance & $119.8 \pm 8.3$ & $116.0 \pm 8.0$ & $115.5 \pm 11.0$ & $126.6 \pm 12.3$ & $122.0 \pm 13.9$ & $119.8 \pm 7.8$ & $125.0 \pm 13.2$ & $120.9 \pm 11.0$ & $\mathrm{p}<0.001$ & Match $4>2^{b}, 3^{b} ;$ Match $7>2^{c}, 3^{c}$ \\
\hline High-intensity & $12.0 \pm 3.3$ & $9.5 \pm 3.2$ & $9.9 \pm 5.6$ & $12.2 \pm 6.7$ & $11.2 \pm 4.6$ & $10.9 \pm 3.6$ & $11.7 \pm 3.9$ & $11.0 \pm 3.2$ & $\mathrm{p}=0.413$ & \\
\hline Moderate-intensity & $20.2 \pm 5.8$ & $18.3 \pm 5.0$ & $18.9 \pm 5.1$ & $19.4 \pm 5.5$ & $19.5 \pm 7.9$ & $20.9 \pm 4.3$ & $21.2 \pm 7.6$ & $18.4 \pm 5.3$ & $\mathrm{p}=0.580$ & \\
\hline Low-intensity & $17.0 \pm 3.2$ & $16.4 \pm 3.8$ & $17.5 \pm 3.1$ & $19.5 \pm 4.9$ & $19.8 \pm 5.1$ & $17.7 \pm 2.0$ & $19.9 \pm 3.8$ & $18.4 \pm 3.3$ & $\mathrm{p}=0.076$ & \\
\hline Light-intensity & $70.6 \pm 2.4$ & $71.8 \pm 3.4$ & $69.3 \pm 2.6$ & $75.5 \pm 3.8$ & $71.5 \pm 3.1$ & $70.3 \pm 2.8$ & $72.2 \pm 3.2$ & $73.1 \pm 3.8$ & $\mathrm{p}<0.001$ & Match $4>1^{\mathrm{a}}, 2^{\mathrm{c}}, 3^{\mathrm{a}}, 5^{\mathrm{c}}, 6^{\mathrm{a}} ;$ Match $8>3^{\mathrm{c}}$ \\
\hline Running with ball & $1.9 \pm 1.9$ & $2.1 \pm 0.8$ & $1.9 \pm 1.0$ & $2.2 \pm 1.0$ & $2.2 \pm 1.4$ & $1.8 \pm 0.7$ & $3.2 \pm 1.7$ & $2.8 \pm 0.9$ & $\mathrm{p}=0.053$ & \\
\hline
\end{tabular}

Distances covered are presented as metres run per minute.

$\mathrm{a}=\mathrm{p}<0.001$

$\mathrm{b}=\mathrm{p}<0.01$

${ }^{c}=\mathrm{p}<0.05$ 
Table 2: Comparison of the means for measures of physical performance in a reference team in matches played before, during and after a prolonged period of fixture congestion of 8 successive matches in 26-days.

\begin{tabular}{lccccc}
\hline $\begin{array}{l}\text { Distances } \\
\text { Covered }\end{array}$ & $\begin{array}{c}\text { Before } \\
\mathrm{n}=9\end{array}$ & $\begin{array}{c}\text { \% difference } \\
\text { in means }\end{array}$ & $\begin{array}{c}\text { During } \\
\mathrm{n}=8\end{array}$ & $\begin{array}{c}\text { \% difference } \\
\text { in means }\end{array}$ & $\begin{array}{c}\text { After } \\
\mathrm{n}=13\end{array}$ \\
\hline Total distance & $120.8 \pm 6.3$ & $-0.2(-2.1-1.7)$ & $120.7 \pm 8.4$ & $+0.1(-1.3-1.5)$ & $120.9 \pm 9.1$ \\
High-intensity & $10.4 \pm 2.6$ & $+5.9(-2.2-14.7)$ & $11.0 \pm 2.9$ & $-0.8(-9.3-8.4)$ & $11.1 \pm 3.8$ \\
Moderate-intensity & $19.2 .2 \pm 3.1$ & $+1.2(-5.4-8.1)$ & $19.6 \pm 4.4$ & $+2.7(-4.6-10.6)$ & $20.1 \pm 4.6$ \\
Low-intensity & $18.8 \pm 2.0$ & $-2.6(-6.6-1.5)$ & $18.3 \pm 2.0$ & $+1.2(-3.1-5.6)$ & $18.6 \pm 2.2$ \\
Light-intensity & $72.4 \pm 1.4$ & $-0.9(-2.0-0.3)$ & $71.8 \pm 1.8$ & $-0.9(-2.7-0.8)$ & $71.1 \pm 1.0$ \\
Running with the ball & $2.4 \pm 0.6$ & $-7.2(-24.7-14.3)$ & $2.3 \pm 0.6$ & $-0.5(-20.4-24.2)$ & $2.3 \pm 0.6$ \\
\hline
\end{tabular}

Distances covered are presented as metres run per minute.

$\%$ difference in means are presented with $95 \%$ Confidence Intervals. 